\title{
Novalis e a natureza: uma leitura de Os discípulos em Saïs, sob a ótica de Rousseau
}

\author{
Karin Volobuef
}

\section{Resumo}

Novalis é conhecido como leitor direto de Kant e, em especial, Fichte. Contudo, percebemos que seu ponto de partida é, a grosso modo, a idéia rousseauniana da felicidade plena em contato com a Natureza. Nessa linha estão diversos textos (por exemplo, Heinrich von Ofterdingen e Die Lehrlinge zu Sais) imbuídos da Sehnsucht por um passado de harmonia e paz entre os homens. Ao contrário de Rousseau, porém, Novalis não vê um homem vivendo isolado e sem consciência de si mesmo, mas acredita em um contato primordial com a Natureza aliado à plenitude espiritual e artística. Arte, religião e amor, portanto, são elementos essenciais para 0 aperfeiçoamento do indivíduo e alicerçam a esperança pelo retorno à Era Dourada.

Palavras-chave: Novalis, Os discípulos em Saïs, Jean-Jaques Rousseau, Natureza,

\begin{abstract}
Novalis is usually known as reader of Kant and specially Fichte. Nonetheless his works show also a clear incorporation of a notion established by Rousseau: the idea of true and absolute happiness brought about by contact with nature. Many texts written by Novalis (such as Heinrich of Ofterdingen and The Novices of Sais) are filled with longing (Sehnsucht) for a past in which mankind experienced harmony and freedom. Nevertheless, Novalis doesn't follow Rousseau's vision of man living lonely e without consciousness of himself. In Novalis' point of view, Nature such as experienced by mankind in ancient times means
\end{abstract}


spiritual and artistic wholeness. Art, religion and love are so crucial for the individual on his way to enhancement and for the yearning to return to the Golden Age of long ago.

Keywords: Novalis, The Novices of Saiis, Jean-Jaques Rousseau, Nature

Novalis, ou Friedrich von Hardenberg (1772-1801), é conhecido como leitor direto de Kant e, em especial, de Fichte. Aliás, o grupo dos primeiros românticos alemães (sediados na cidade de Iena) teve como fator de aglutinação justamente o intuito de ler e discutir em conjunto a Wissenschaftslebre, ou Doutrina da ciência, que J. G. Fichte havia publicado em 1794 .

0 interesse do grupo pelas idéias filosóficas, no entanto, não se restringe aos pensadores alemães. A obra do genebrino Jean-Jacques Rousseau foi, igualmente, uma fundamental hélice a propelir a reflexão de românticos como Novalis, Friedrich Schlegel, E. T. A. Hoffmann, Adelbert von Chamisso, etc.

Nesse sentido, o presente texto busca explorar alguns aspectos da obra de Novalis que dialogam com traços do pensamento de Rousseau. Para começar, não apenas Novalis, mas todo o Romantismo alemão acalentou a idéia de uma "Idade de Ouro" em que os homens teriam tido acesso a uma vida mais plena e feliz. Contudo, se para Rousseau o estado de natureza implica em exclusão da Razão, da linguagem, do convívio social e da consciência da própria individualidade, para os românticos de Iena, a Idade de Ouro teria possibilitado o desenvolvimento irrestrito das aspirações individuais, a dedicação integral ao aprofundamento da sensibilidade e a convivência harmônica entre o artístico e o prático. A Idade de Ouro estaria, além disso, despida das convenções sociais (como a moral burguesa) que limitam as condiçóes para a realização pessoal, e das imposições (como casamento tradicional, trabalho com fins práticos e lucrativos) que afastam o indivíduo da dedicação à arte e ao pensamento. Para os primeiros românticos, uma vida intensa e completa só é possível em uma situação liberta de obrigações que refreiam seu desenvolvimento pessoal.

Como se vê, Rousseau entende a felicidade como um estado impossível de ser alcançado dentro da sociedade - qualquer sociedade. O homem feliz é aquele com desejos simples (ligados à satisfação das necessidades básicas, como alimento, repouso, etc.), os quais podem ser saciados imediatamente, pois, vivendo em ambiente natural, o homem encontra aí com facilidade e rapidez tudo o que precisa. Rousseau, portanto, concebe a felicidade humana dentro de uma situação que desliga do homem os traços que o distinguem dos animais: racionalidade, imaginação, sociabilidade.

Para o romântico, ao contrário, a perspectiva se desloca: o grande empecilho para a felicidade não é a sociedade como tal, mas a sociedade burguesa - que regula e predetermina o trabalho (que deve ser sistemático e útil do ponto de vista da rentabilidade) e as relações de convivência (casamento, amizade). Além disso, a grande preocupação do romântico é com a situação do artista e da própria arte, cuja essência específica o burguês muitas vezes não consegue captar ou valorizar conforme seria a expectativa do romântico.

No que se refere à Natureza, varia bastante entre os românticos alemães a importância e o papel atribuídos a ela. Em geral, a Natureza enquanto ambiente natural é bastante tematizada, especialmente sob forma da paisagem noturna, tendo em vista que ela deixa margem para o mistério e para o fantástico. Quanto a Novalis, o romance ina- 
cabado Die Lehrlinge zu Sais, ou Os discípulos em Saïs, é um texto diretamente voltado para a discussão da Natureza, sendo que em carta de 23.02.1800, escrita em Weißenfels e dirigida a Ludwig Tieck, Novalis refere-se a esse romance como Naturroman ou romance da Natureza $(1999$, v. 1, p. 732).

As primeiras anotações para Os discípulos em Saïs datam de 1798. Depois da morte do autor em 1801, o fragmento veio a lume no ano seguinte, sendo composto de duas partes: "O aprendiz" e "A Natureza", totalizando cerca de 25 páginas. O texto não conta com um enredo propriamente dito, apenas uma sequiência de digressóes, poucos trechos narrativos, diálogos.

A situação remonta aos antigos filósofos gregos: o narrador não identificado nem descrito é um dos discípulos reunidos em Saïs para ouvir os ensinamentos do mestre (do qual igualmente não sabemos a identidade nem temos qualquer descrição).

O texto inicia com as palavras:

Os homens percorrem caminhos diferentes; quem se der a seguilos e a compará-los, verá surgir estranhas figuras; figuras, dir-seá, que fazem parte daquela escrita difícil e caprichosa que em todo o lado se encontra: nas asas, na casca dos ovos, nas nuvens, na neve, nos cristais, na forma das rochas, na água gelada, dentro e fora das montanhas, das plantas, dos animais, dos homens, nos resplendores do céu, nas placas de vidro e de resina quando são esfregadas e as apalpamos; nas limalhas que aderem ao imã e nas estranhas conjecturas da sorte... pressente-se a chave e a gramática dessa escrita singular [...] $\left(1989\right.$, p. 31) ${ }^{1}$

O homem e a Natureza fazem parte de uma entidade maior, de uma esfera que envolve o palpável e o impalpável, o cognoscível e o misterioso, o que está à mão e o que é inalcançável. Essa esfera é ilimitada, infinita. Diante desse infinito inatingível resta ao romântico a interminável busca, o anseio nunca satisfeito, o ideal nunca concretizado. A marca da incompletude está atrelada em Novalis à própria concepção de filosofia que, conforme percebemos em um de seus aforismos, está atrelada à idéia de insatisfação: "A filosofia em realidade é saudade de casa, ou anseio de, em toda parte, estar em casa" (minha tradução) ${ }^{2}$. Da mesma forma também é o aspecto fundamental da Natureza, conforme lemos em outro aforismo:

"Somente o que é incompleto pode ser compreendido, pode nos conduzir adiante. $O$ que é completo pode apenas ser desfrutado. Se quisermos compreender a Natureza é necessário que a vejamos como incompleta a fim de chegarmos a um item de permuta desconhecido. Toda definição é relativa" ${ }^{\text {"N }}$ (Novalis,

1 „Mannigfache Wege gehen die Menschen. Wer sie verfolgt und vergleicht, wird wunderliche Figuren entstehen sehen; Figuren, die zu jener großen Chiffernschrift zu gehören scheinen, die man überall, auf Flügeln, Eierschalen, in Wolken, im Schnee, in Kristallen und in Steinbildungen, auf gefrierenden Wassern, im Innern und Äußern der Gebirge, der Pflanzen, der Tiere, der Menschen, in den Lichtern des Himmels, auf berührten und gestrichenen Scheiben von Pech und Glas, in den Feilspänen um den Magnet her, und sonderbaren Konjunkturen des Zufalls erblickt. In ihnen ahndet man den Schlüssel dieser Wunderschrift [...]“(Novalis, 1956, p. 29).

2 „Die Philosophie ist eigentlich Heimweh - Trieb überall zu Hause zu sein.“ (Novalis, 1956, p. 153)

3 "Nur das Unvollständige kann begriffen werden, kann uns weiterfïhren. Das Vollständige wird nur genossen. Wollen wir die Natur begreifen, so müssen wir sie als unvollständig setzen, um so zu einem unbekannten Wechselgliede zu gelangen. Alle Bestimmung ist relativ." (Novalis, 1956, p. 156) 
Em Os discípulos em Saïs, por meio dos diálogos e digressões ali inseridos, Novalis contrapõe várias formas de encarar a Natureza e lidar com ela. Basicamente temos duas posturas opostas: de um lado, a Natureza vista como algo sagrado; por outro, a perspectiva que se guia pela experiência mais imediata e concreta e que se destina a fins utilitários. Tal divisão nos é apresentada no texto como tendo ocorrido desde os primórdios da humanidade:

Já na infância dos povos se encontravam almas graves, para quem a Natureza era realmente a face de uma divindade, e coraçōes mais frívolos que só a recordavam pelas suas festas. 0 ar sabia-lhes a bebida que embriaga; as estrelas pareciam archotes das suas danças nocturnas; as plantas e os animais só eram alimentos preciosos; e a Natureza, em vez de sereno e maravilhoso templo, transformara-se em cozinha e jovial despensa. (Novalis, 1989, p. 44) ${ }^{4}$

E quem sabe louvar a Natureza e reconhecê-la como templo sagrado é o poeta, sempre pronto para revitalizá-la, a fazê-la renascer. Em oposição a ele, o cientista ou homem de saber é aquele que investiga a Natureza, acreditando poder entendê-la sem perder nenhum detalhe. Nesse meticuloso processo de investigação, no entanto, a Natureza fica reduzida a pedaços sem vida, agitados apenas por alguns movimentos convulsivos (Novalis, 1956, p. 33; Novalis, 1989, p. 42). Daí ser a poesia o meio mais adequado de conhecer a Natureza, uma vez que é em poemas que ela mais generosamente deixa entrever sua verdadeira essência (Novalis, 1989, p. 41; Novalis, 1956, p. 33).

Além do discípulo que fala de sua permanência em Saïs na primeira parte do romance (intitulada "O aprendiz"), na segunda parte ("A Natureza") outros personagens aparecem n’Os discípulos em Sä̈s. As falas desses outros discípulos, entretanto, aparecem indistintamente, sem informações sobre quem está falando. Uma dessas vozes não identificadas pronuncia-se sobre a Natureza enquanto grande conselheira e guia daqueles que estão dispostos a aprender com ela:

Quem pertencer a tal raça e tiver esta fé, quem quiser participar neste desbravar da natureza, deverá frequentar o estúdio do artista, ouvir a insuspeitada poesia que se filtra por todas as coisas, nunca se mostrar cansado de contemplar a Natureza nem de manter com ela relações, em todo o lado deverá seguir-lhe os conselhos, não se furtar a penosas caminhadas, quando ela o chamar, mesmo que seja forçoso transpor lamaceiros; por certo encontrará tesouros indizíveis; no horizonte já surge a lanterna do mineiro. E quem saberá dizer em quantos celestiais segredos pode iniciá-lo uma maravilhosa habitante dos reinos subterrâ-

4 „Schon unter den kindlichen Völkern gab's solche ernste Gemüter, denen die Natur das Antlitz einer Gottheit war, indessen andre fröhliche Herzen sich nur auf sie zu Tische baten; die Luft war ihnen ein erquickender Trank, die Gestirne Lichter zum nächtlichen Tanz, und Pflanzen und Tiere nur köstliche Speisen, und so kam ihnen die Natur nicht wie ein stiller wundervoller Tempel, sondern wie eine lustige Küche und Speisekammer vor." (Novalis, 1956, p. 34-35) 
neos? (Novalis, 1989, p. 46) 5

Nesse trecho percebemos a Natureza como iluminação, mestre e inspiração do ser humano. A observação do mundo concreto não exclui, antes convida à experiência do mágico e misterioso.

Dentre os personagens não identificados que se fazem ouvir também há um para quem a Natureza é uma força bruta: cega e cruel, ela é o anjo da morte, a origem da destruição, a fatalidade que se abate sobre o destino humano (Novalis, 1956, p. 36-37; Novalis, 1989 , p. 48-49). Quem efetivamente a compreendesse seria engolido pelas trevas da loucura e o próprio anseio por uma compreensão desse mecanismo monstruoso já arrebata o curioso para um turbilhão de vertigem. Dessa perspectiva, a Natureza equivale às trevas e ao aniquilamento da Razão humana. Aproximar-se dela - convivendo com animais, vegetais, rochas e nuvens - leva à dissolução do divino e humano e significa entregar-se ao redemoinho avassalador do embrutecimento.

Os aspectos irracionais, portanto, estão representados n'Os discípulos em Saï com traços pesados e negativos. Aqui fica evidente talvez o momento de maior oposição em relação a Rousseau: enquanto este via na civilização a origem de todos os males, para este personagem de Novalis a irracionalidade, a proximidade com o mundo natural representa a destruição daquilo que distingue o homem dos animais e define sua relação com o sagrado.

Contrapondo-se a essa perspectiva, porém, outras vozes se pronunciam e uma delas pergunta: "Será possível que não reconheçam na Natureza a fiel cópia de si próprios?" (Novalis, 1989, p. 51; Novalis, 1956, p. 38). De acordo com o personagem, "O sentido do mundo é a Razão: por causa dela ele existe" (minha tradução) ${ }^{6}$ e um dia o mundo será palco da manifestação de uma recém-desabrochada "Razão infantil", servindo-lhe de "imagem divina e cenário de uma verdadeira igreja" (Novalis, 1956, p. 38-39 - minha tradução). Nesse ponto percebe-se que o texto atingiu seu cume em termos de exposição acerca das maneiras de encarar a Natureza. Tendo falado já da Idade do Ouro (passado), aqui o texto traz, nas palavras do personagem um vaticínio sobre o futuro papel do mundo e sua relação com o sujeito. Este é pensante, racional - mas não segue o tipo de perspectiva do cientista que aborda a Natureza com o bisturi em mãos ${ }^{7}$. Sua ótica, ao contrário é "infantil”, ou seja, dotada de uma sensibilidade e capaz de uma intuição que se irmanam com as do poeta e do verdadeiro amante da Natureza. Essa Razão não pretende despedaçar a Natureza (para ver melhor sua constituição), pois reconhece nela a imagem simbólica, ou seja, o reflexo externo de si mesma. Essa Razão comunga com a Natureza como uma parte dela própria. ${ }^{8}$

5 "Wer dieses Stamms und dieses Glaubens ist und gern auch das seinige zu dieser Entwilderung der Natur beitragen will, geht in den Werkstätten der Künstler umher, belauscht überall die unvermutet in allen Ständen hervorbrechende Dichtkunst, wird nimmer müde, die Natur zu betrachten und mit ihr umzugehen, geht überall ihren Fingerzeigen nach, verschmäht keinen mühseligen Gang, wenn sie ihm winkt, und sollte er auch durch Modergrüfte gehen: er findet sicher unsägliche Schätze, das Grubenlichtchen steht am Ende still, und wer weiß in welche himmlische Geheimnisse ihn dann eine reizende Bewohnerin des unterirdischen Reichs einweiht." (Novalis, 1956, p. 35-36)

6 "Der Sinn der Welt ist die Vernunft: um derentwillen ist sie da" (Novalis, 1956, p. 38).

7 „mit scharfen Messerschnitten“" (Novalis, 1956, p. 33).

8 "Der Sinn der Welt ist die Vernunft: um derentwillen ist sie da, und wenn sie erst der Kampfplatz einer kindlichen, aufblühenden Vernunft ist, so wird sie einst zum göttlichen Bilde ihrer Tätigkeit, zum Schauplatz einer wahren Kirche werden." (Novalis, 1956, p. 38-39). 


\section{outraTravessia}

As palavras finais do personagem são eloquentes:

Quem portanto quiser alcançar o conhecimento da Natureza, que cultive seu sentido moral, aja e modele conforme a essência nobre de seu íntimo. Em decorrência, a Natureza irá descortinarse como por si mesma diante dele. A ação moral é aquele grande e único ensaio no qual todos os enigmas dos mais variados fenômenos se resolvem. Quem o compreender e souber decompô-lo em rígidas sequiências lógicas, será um eterno mestre da Natureza (minha tradução) ${ }^{9}$

Essas considerações estão em consonância com o fragmento 16 de Pólen, publicado na Atbenäum em 1798:

Sonhamos com viagens através do todo cósmico: então o universo não está dentro de nós? As profundezas de nosso espírito nós não conhecemos. - Para dentro vai o misterioso caminho. Em nós, ou em parte nenhuma, está a eternidade com seus mundos, o passado e o futuro. (Novalis, 1988, p. 42 e 44) ${ }^{10}$

Esse "caminho para dentro" é trilhado em Os discípulos em Saïs no pequeno conto de fadas que um discípulo narra para outro que ouvira as considerações dos demais sobre a Natureza e agora se encontrava mergulhado em profundas reflexões, solitário e confuso devido à multiplicidade de opinióes que presenciara. $\mathrm{O}$ recém-chegado aproxima-se daquele mais sisudo e, a fim de convencê-lo a reunir-se aos outros, conta a história de Hyazinth und Rosenblütchen ou Jacinto e Rosinba.

A narrativa remete a um passado longínquo, provavelmente a Idade de Ouro, e a situação parece conter fortes ecos das idéias rousseaunianas. Como se vivesse em um paraíso perfeito, os personagens convivem em perfeita concórdia e tranquiilidade não apenas entre si, mas também com os seres e coisas da Natureza. Os protagonistas, Jacinto e Rosinha, conforme os próprios nomes já anunciam, são humanos e flores; $\mathrm{e}^{\mathrm{t}}$ as flores, frutas, animaizinhos e rochedos são, por sua vez, também humanos. Tudo é compartilhado igualmente por humanos, animais, vegetais e coisas: a fala, os folguedos, $o$ afeto generoso.

A ruptura dessa situação paradisíaca é provocada pela chegada de um homem misterioso que dá um livro de presente a Jacinto. Como resultado, o rapaz se torna sisudo, perde interesse pelos jogos dos companheiros e afasta-se de Rosinha, a quem estivera ligado por profundo afeto. Símbolo da cultura civilizada, da investigação científica, da ordenação lógica do conhecimento, o livro causa enorme perturbação em Jacinto e introduz o estranhamento entre ele e os que o rodeiam. A Natureza continua ali, mas Jacinto tornou-se incapaz de conviver com ela como até então.

9 Wer also zur Kenntnis der Natur gelangen will, übe seinen sittlichen Sinn, handle und bilde dem edlen Kerne seines Innern gemäß, und wie von selbst wird die Natur sich vor ihm öffnen. Sittliches Handeln ist jener große und einzige Versuch, in welchem alle Rätsel der mannigfaltigsten Erscheinungen sich lösen. Wer ihn versteht und in strengen Gedankenfolgen ihn zu zerlegen weiß, ist ewiger Meister der Natur." (Novalis, 1956, p. 39)

10 „Wir träumen von Reisen durch das Welt all: ist denn das Weltall nicht in uns? Die Tiefen unsers Geistes kennen wir nicht. - Nach Innen geht der geheimnisvolle Weg. In uns, oder nirgends ist die Ewigkeit mit ihren Welten, die Vergangenheit und Zukunft." (Novalis, 1999, v. 2, p. 233). 
Quem indica o remédio para sua condição é uma anciã que mora na floresta. Representante da intuição e sensibilidade intimista, ela lança o livro às chamas $\mathrm{e}$ o aconselha a partir pelo mundo em busca da deusa Ísis. Durante essa viagem, a paisagem é descrita mas em termos estilizados e seguindo um ritmo de transformação que acompanha simetricamente as mudanças de espírito de Jacinto: ela vai se acalmando e, ao mesmo tempo, o ambiente torna-se mais alegre e suave (tempestades e desertos são substituídos pelos verdes e agradáveis campinas).

Após receber instruções de uma nascente de águas e um grupo de flores que encontrou pelo caminho, Jacinto chega ao templo da deusa ísis. Adormecendo ele penetra no recinto e aproxima-se da deusa coberta por um véu. Ao erguê-lo, reconhece as feições de Rosinha, com quem se casa e tem muitos filhos.

Como se vê, a viagem de Jacinto termina com o encontro consigo mesmo. A felicidade e paz são alcançadas no recinto sagrado, cujo acesso não se dá no mundo externo, mas no espaço interno e onírico. E o autoconhecimento é pré-requisito para o contato com o sagrado e com o amor. Ao fim, a Natureza paradisíaca é reencontrada.

Ao contrário de Rousseau - para quem o estado de natureza é irrecuperável -, em Novalis há a perspectiva de um retorno à Idade de Ouro, à felicidade sem perturbações, à realização plena do homem em contato com a Natureza. Tal perspectiva, aliás, ecoa no aforismo: "A Natureza é um ideal. O verdadeiro ideal é possível, real e necessário ao mesmo tempo." ${ }^{11}$ (Novalis, 1956, p. 159 - minha tradução)

Na verdade, as peripécias de Jacinto - narradas a um discípulo em Saï - retomam as palavras do preceptor no Emílio, quando ele se despede de seu discípulo no Livro V dizendo:

Enquanto não soubermos o que fazer, a sabedoria consiste em permanecer inativo. [...] Buscar a felicidade sem saber onde ela está é expor-se ao perigo de fugir dela e correr tantos riscos de encontrar o oposto da felicidade quantos há estradas nas quais perder-se. Mas não são todos que sabem como refrear-se da ação. Na ansiedade em que o desejo pelo bem-estar nos coloca, nosso erro consiste mais em persegui-lo do que não fazer nada para alcançá-lo; e, uma vez abandonado o lugar onde podemos conhecê-lo, não sabemos mais como retornar para lá. (Rousseau, 1979, p. 442 - minha tradução)

Ao deparar-se com o livro desconhecido, Jacinto entrou em contato com aquilo que ultrapassava o círculo de sua experiência. A felicidade pareceu-lhe então estar para além das fronteiras que até ali haviam delimitado sua vida. Seu estranhamento frente às pessoas e seres ao seu redor equivalem já a um afastamento, a um abandono do lugar conhecido. Ao contrário do que lemos em Rousseau, entretanto, em Novalis o retorno foi possível.

Para isso, uma seqüência de etapas criaram as condições necessárias. Em primeiro lugar, Jacinto visitou a anciã da floresta, que representa o pólo feminino e intuitivo em contraste com o homem do livro, estando ligada a forças primordiais de vida e criação da Natureza (floresta, fogo). Por intermédio dela, Jacinto não irá vaguear

11 „Die Natur ist das Ideal. Das wahre Ideal ist möglich, wirklich und notwendig zugleich.“ (Novalis, 1956, p. 159) 
ao acaso, pois sabe o destino que deverá alcançar para encontrar a cura de seu mal: a morada da deusa Ísis. Os conselhos da anciã, na verdade, não impelem Jacinto para fora ou para longe, mas ensinam-lhe que sua viagem deve ser rumo a si mesmo, rumo ao seu próprio interior.

A segunda etapa consiste no encontro com a fonte e as flores, elementos da Natureza que também simbolizam a vida e o renascimento (água, primavera). Eles o instruem quanto à direção específica que deverá seguir. Na verdade, passado o período de busca interior e de gradual apaziguamento da inquietação, Jacinto mostra-se pronto para a revelaçāo final. A revelação - o levantar do véu - não significa a descoberta do inusitado ou desconhecido, mas uma nova percepção daquilo que já se tinha à mão.

Tanto em Rousseau como em Novalis, o ideal teria sido se a serenidade primordial e a inocência nunca tivessem sido perdidas. Uma vez acontecido isso, porém, a busca torna-se imprescindível em Novalis, enquanto Rousseau recomenda a inatividade. Nesse ponto, Rousseau mostra-se "conservador" e oposto aos românticos, que sempre aspiram ao distante horizonte azul.

\section{Referências bibliográficas}

1985.

KLOTZ, Volker. Das europäische Kunstmärchen. Stuttgart: J. B. Metzler,

KNIEP, Claudia. Gans - Bach - Stein. Zu einem Satz in Novalis' Die Lebrlinge zu Sais. Wirkendes Wort. Bonn, v. 34, n. 6, p. 409-410, nov/dez 1984.

Pólen; Fragmentos, diálogos, monólogo. Tradução, apres. e notas Rubens Rodrigues Torres Filho. São Paulo: Iluminuras, 1988. (Biblioteca Pólen). . Os discípulos em Sä̈s. Tradução de Luís Bruhein. Lisboa: Hiena, 1989. . Scbriften. Werke, Tagebücher und Briefe Friedrich von Hardenbergs. Hrsg. von Hans-Joachim Mähl und Richard Samuel. Kommentar von Hans Jürgen Balmes. Darmstadt: Wissenschaftliche Buchgesellschaft, 1999. $3 \mathrm{v}$.

ROUSSEAU, Jean-Jacques. Emile or On Education. Introduction, Translation and Notes by Allan Bloom. [s.l.]: Basic Books, 1979. p. 442.

WÜHRL, Paul-Wolfgang. Das deutsche Kunstmärchen. Heidelberg: Quelle \& Meyer, 1984. (Uni-Taschenbücher für Wissenschaft; UTB 1341). 